\title{
FANCat: French affective norms for ten emotional categories
}

\author{
Arielle Syssau ${ }^{1} \cdot$ Adil Yakhloufi $^{1} \cdot$ Edouard Giudicelli $^{1} \cdot$ Catherine Monnier $^{1} \cdot$ Royce Anders $^{2}$
}

Published online: 31 July 2020

(C) The Psychonomic Society, Inc. 2020

\begin{abstract}
The present study develops key research for French word norms that combines the predominant theories of dimensional and discrete (or categorical) emotions. As a result, we provide the database FANCat, affective norms for a set of 1031 French words on ten discrete emotion categories: fear, anger, disgust, sadness, anxiety, awe, excitement, contentment, amusement, and serenity. FANCat complements a previous word set, FAN, which provides only the dimensional norms, valence, and arousal (Monnier \& Syssau, 2014). Herein, we introduce five discrete positive emotions in efforts to differentiate positive emotions at higher resolution and specificity. Although ten emotional categories were considered in FANCat norms, results showed a high degree of inter-rater reliability and a good external validity. Then, distributional analyses of words into the ten emotion categories revealed that positive words evoked mainly the emotions awe, contentment, and amusement, and principally evoked either one positive emotion only ("pure" words) or two (mixed words). This study contributes to a deeper understanding of the relationship between language, and negative and positive emotions. It is also currently the only norms database in French that analyses ten discrete emotions as well as including valence and arousal. FANCat is available at https://www.researchgate.net/publication/ 338622765_FANCat_database.
\end{abstract}

Keywords Affective norms $\cdot$ Discrete emotion categories $\cdot$ Positive and negative emotions

Many studies that seek to understand how the affective characteristics of words may influence their processing, rely on tasks that require norm lists, like the one developed herein. Currently, there are two types of norms that are useful for characterizing the affective meaning of words: dimensional and categorical norms.

The most widely used dimensional norms list is currently known as Bradley and Lang's (1999) Affective Norms for English Words (ANEW), which provides valence, arousal, and dominance norms for 1034 English verbs, nouns, and adjectives. Bradley and Lang carried out their work within a framework of dimensional characterization of emotions, initially proposed by Wundt (1896) and revived by Osgood, Suci, and Tannenbaum (1957). According to this perspective, all emotional experiences can be characterized according to three dimensions: valence (which ranges from positive to

Arielle Syssau

arielle.syssau@univ-montp3.fr

1 Univ Paul Valéry Montpellier 3, Univ Montpellier, EPSYLON EA 4556, F34000 Montpellier, France

2 Univ Lyon. 2, Laboratoire d'Etude des Mécanismes Cognitifs (EA 3082), 5, avenue Pierre Mendès-France, F69676 Bron, France negative), arousal (which ranges from calm to exciting), and dominance (which ranges from in control to out of control). This three-dimensional affective model was later reduced to a two-dimensional model, relying solely on the valence and arousal dimensions (Russell, 2003).

The ANEW dimensional norms database has since been adapted into several languages, including German (Affective norms for German sentiment terms, ANGST, Schmidtke, Schröder, Jacobs, \& Conrad, 2014), Spanish (The Spanish adaptation of ANEW, Redondo, Fraga, Padrón, \& Comesaña, 2007), Italian (Fairfield, Ambrosini, Mammarella, \& Montefinese, 2017; Montefinese, Ambrosini, Fairfield, \& Mammarella, 2014), Polish (Affective norms for Polish words, ANPW, Imbir, 2015) and Portuguese (Soares, Comesaña, Pinheiro, Simões, \& Frade, 2012). Affective databases have been also proposed in other languages, such as Dutch (Moors et al., 2013), Finnish (Eilola \& Havelka, 2010) and French (Affective Norms for French words, FAN, Monnier \& Syssau, 2014).

In 2007, Stevenson, Mikels and James provided complementary data for ANEW by collecting categorical ratings of the entire set of 1034 English words. This categorical approach to classifying emotions was initially proposed by Charles Darwin (1872), developed by Ekman (1993), and then further by Panksepp, who was among the first to suggest that 
dimensional and categorical approaches are not mutually exclusive, and can be used in combination to have a more complete view of emotions, by proposing the "Hierarchical emotion theory" (Panksepp, 1998, 2007; Panksepp \& Biven, 2012). Categorical, or discrete, approaches describe emotions as a limited set of functionally distinct categories of emotions, with partially distinct neural correlates (e.g., for disgust, see Ponz et al., 2013). The usefulness of discrete emotional categories norms was previously demonstrated with picture stimuli, such as those provided in the International Affective Picture Systems (IAPS, Lang, Bradley, \& Cuthbert, 2005), and were shown to produce different responses in skin conductance or heart rate, depending on their emotional category (like disgust, sadness, or fear, Bradley, Codispoti, Sabatinelli, \& Lang, 2001). Following on the development of categorical norms for all the IAPS images (Mikels et al., 2005), Stevenson, Mikels, and James (2007) then provided similar complementary data for the ANEW norms (Bradley \& Lang, 1999), by collecting categorical ratings for the entire 1034word set on happiness, sadness, fear, disgust, and anger, which have been recognized as a set of cross-culturally universal basic emotions (Ekman, 1993; Levenson, 2003). By adding a study of affective norms for the words in the ANEW database, Stevenson et al. (2007) provided a means to investigate both views with one set of stimuli, since the ANEW database originally included the classical norms for the three dimensions: valence, arousal and dominance.

The heterogeneity of the relationships between each emotional category, and the dimensions of valence, arousal, and dominance, led Stevenson and his colleagues to highlight the importance of using the by-emotion categorical data as a supplement to the classical dimensional data. Then shortly after, Strauss and Allen (2008) further investigated categorical norms by providing categorization ratings for a set of 463 English words with up to eight categories rather than five. That is, their categorization instructions required participants to select one of the following eight discrete emotional categories: happiness, sadness, anger, anxiety, fear, disgust, neutral and surprise, that they felt most highly represented the word. Hence, principally (apart from neutral), Strauss and Allen added anxiety and surprise to the five emotions studied by Stevenson et al. (2007) to take into account previous disagreements about which emotions are in fact basic. This collection of emotional categorical ratings has since been adapted in German, Polish, Turkey, Spanish, and French languages.

For example, Briesemeister, Kuchincke, and Jacobs (2011) provided researchers with a list of reliable discrete emotion norms for 2000 German nouns by collecting ratings on the same emotion categories than those used to enrich the ANEW database (happiness, sadness, fear, disgust, and anger) and with the same five-point scales. This discrete emotion norms list for nouns (DENN-BAWL), completed two previous dimensional norms lists: the Berlin Affective Word List
(BAWL, Võ, Jacobs, \& Conrad, 2006) and the BAWL-R (Võ et al., 2009). Notably, this German norms study revealed a negative correlation between German happiness and arousal ratings, which was not observed in English norms. Briesemeister et al. hence suggested that DENN-BAWL would not only allow investigations with German-speaking participants, but may also trigger cross-cultural comparisons. In addition to providing categorical norms, Briesemeister et al. also demonstrated that categorical emotion variables account for significant variance in lexical decision task performance. For example, words with high scores in happiness or fear were associated with significant differences in both response times and the mean sum of errors, despite the fact that the words were controlled for the emotional dimensions, valence, and arousal. Specifically, high-happiness words were correctly recognized faster than low-happiness words.

By using a lexical decision task in their study, Briesemeister et al. documented the usefulness of considering categorical norms to understand differences in human performance. Since the Nencky Affective Word List (NAWL, Riegel et al., 2015) is an adaptation of the German database for Polish, Wierzba et al. (2015) were able to augment the NAWL with seven-point scales for happiness, anger, sadness, fear and disgust ratings for 2907 Polish words. More recently, Kapucu, Kılıç, Özkılıç-Kartal, and Sarıbaz (2018) provided a similar norms list for arousal, valence, and discrete emotion categories for 2031 Turkish words.

For Spanish words, Hinojosa, Martinez-Garcia, et al. (2016) introduced the Madrid Affective Database (MADS). This word set contained 875 Spanish words (verbs, nouns, adjectives) that were rated on two dimensions (valence and arousal) and on five emotional categories (happiness, anger, sadness, fear, and disgust) by 660 Spanish native speakers. The five emotions were presented with the same five-point scales as those used by Stevenson et al. (2007) and Briesemeister et al. (2011).

Then, 1 year later, Ferré, Guasch, Martinez-Garcia, Fraga, and Hinojosa (2017) published a larger dataset containing ratings on five-point scales for five emotional categories (happiness, anger, fear, disgust, and sadness) for a set of 2266 Spanish words. They collected emotional category ratings for Spanish words already rated from a dimensional perspective in three previous norms lists (Ferré, Guasch, Moldovan, \& Sánchez-Casas, 2012; Guasch, Ferré, \& Fraga, 2015; Redondo et al., 2007). Following Hinojosa, Martinez-Garcia et al. (2016), Ferré et al. (2017) examined the distribution of words among these emotional categories. Specifically, Ferré et al. classified the ratings into two groups: low level (mean ratings lower than or equal to 2.5) and high level (mean ratings higher than 2.5). They reported a distributional pattern that was highly consistent with the data of Hinojosa, MartinezGarcia et al. (2016) and found a large pool of words associated with happiness, as well as lower percentages of words 
belonging to each negative emotion (i.e., happiness, $32.37 \%$, anger, $5.84 \%$, sadness, $8.43 \%$, fear, $11.16 \%$, and disgust, $4.61 \%$ ). Words with low values in the five emotions were considered neutral words $(37.59 \%)$. Furthermore, Ferré et al. (2017) introduced a noteworthy analytical approach for other researchers, by assigning words with high mean ratings to "pure" or "mixed" words categories. Specifically, they wanted to know whether the words were mainly assigned to one emotion (i.e., pure words) or to more than one emotion (i.e., mixed words). Their analysis revealed that $95.52 \%$ of happinessrelated words were pure. In contrast, only $11.43 \%$ of all words related to the four negative emotions were pure. To explore the heterogeneity of negative words, Ferré et al. applied the Proxscal Procedure for Multidimensional Scaling (MDS, Busing, Commandeur, \& Heiser, 1997). The findings reported revealed differences among the emotional categories. For example, mixed sad words combined mainly fear and sadness, whereas disgust words were the most distinct; they overlapped the least with the other negative emotions. Finally, Stadthagen-Gonzales et al. (Stadthagen-González, Ferré, Perez-Sanchez, \& C.,, \& Hinojosa, J. A., 2018) provided the largest set of emotional category ratings in any language by providing norms for 10,491 Spanish words for the five emotions categories previously studied; these ratings were collected from 2010 native Spanish speakers. Following Ferré et al. (2017), they classified the ratings for each emotion as "high" when the average rating was three or more. ${ }^{1}$ Note that this threshold (corresponding to the middle of the scale) is higher than the 2.5 used in previous studies. Nevertheless, their findings were consistent with previous studies, and likewise showed that the number of words included in the happiness category was larger than the number of words included in negative emotional categories. Stadthagen-Gonzáles et al. also examined the repartition of emotional words in the two types of words proposed by Ferré et al. (2017), namely pure words and mixed words. Their findings were consistent with those reported by Ferré et al. (2017). All words with average ratings higher than 3 for the happiness category were pure words, whereas a large part of words in negative emotional categories were mixed.

To our knowledge, only two norms for discrete emotional categories are available for French words. First, Ric, Alexopoulos, Muller, and Aubé (2013) provided a database of emotion-related dimensions for 524 French trait words. Measures included valence, approach/avoidance tendencies associated with the trait, possessives and other like-relations of the trait, and discrete emotions conveyed by the trait (i.e., anger, disgust, fear, happiness, and sadness) on five sevenpoint scales (for 1: does not convey this emotion at all to 7: strongly conveys this emotion). Second Gobin, Camblats, Faurous, and Mathey (2017) provided measures of valence,

${ }^{1}$ This same threshold of 3 or more is used herein. arousal, and emotional categories for 1286 French words according to age. In this database, the emotional categories were rated separately for negative and positive words. Participants had to decide which negative emotions the negative words referred the most to, between the options: anger, disgust, sadness, or fear; and which positive emotions the positive words referred the most to, between surprise and happiness. Although these two databases are indispensable tools for French-speaking researchers investigating the influence of words' affective characteristics on how these words are processed, they have limitations. The first limitation concerns the particularity of the list of words (only trait words) and the second limitation is that they do not use a response scale that distinguishes words for whether they are strongly or weakly within a particular emotional category. Such distinctions can be crucial in studying the influence of affective characteristics on word processing. For example, Briesemeister et al. (2011) showed that high-happiness words are correctly recognized faster than low-happiness words.

The aim of the present work is to provide similarly important and detailed information to the principal dimensional norms database in French, known as French Affective Norms (FAN, Monnier \& Syssau, 2014). FAN provides affective norms for a large corpus of French nouns and adjectives $(N=1031)$ that were rated on emotional valence and emotional arousal by 469 French young adults. In the present normative study, we collected categorical ratings for each of ten emotions on the entire set of FAN, which we term FANCat.

FANCat constitutes an important research tool that gains further interest by its novel inclusion of additional positive emotion categories. These additional emotion categories are motivated by recent previous work such as Shiota et al. (2017), who in a publication with the evocative title "Beyond happiness: Building a Science of discrete Positive Emotions," underline the importance of differentiating among several discrete positive emotions, instead of principally "happiness". They wrote that "it is no longer tenable to assume that all positive emotions have identical response profiles or effects upon motivation and cognition". However, in the majority of emotional category norm studies discussed here, only one positive emotion "happiness" is proposed to the participants, and their results lead to conclude that positive words were the most consistently related to one single discrete emotion, which is to say, happiness. This is thus a significant, potential confound to be examined. For example, only Strauss and Allen (2008), and Gobin et al. (2017) examined an additional positive emotion by proposing the discrete emotion "surprise" to the participants. Gobin et al. observed then that $5.1 \%$ of the 1066 words considered were surpriserelated words and $1.6 \%$ of these words were also happiness-related words. This last result led to an 
important speculation that there may be "mixed" positive words, if only researchers examined additional categories of positive discrete emotions.

To our knowledge, only one emotional categorical norms study examined a larger variety of positive discrete emotions: the norms provided by Mikels et al. (2005), which made available this categorical data for the IAPS. For this study, Mikels et al. (2005) conducted a pilot study in order to determine which emotional labels were generated from the IAPS images when participants were unconstrained. Two subsets of images were selected and examined separately: the positive and the negative subsets. For the positive subset: 187 images were selected as positively valenced IAPS images. Twenty participants were allowed to use as many emotional labels as they needed to describe their emotional reaction from each image presented on a computer screen. The ten most-cited positive emotions were: awe $(24.30 \%)$, amusement $(11.54 \%)$, happiness $(7.64 \%)$, excitement $(7.20 \%)$, contentment $(6.98 \%)$, interest $(3.01 \%)$, desire $(2.94 \%)$, curiosity $(1.81 \%)$, peacefulness $(1.64 \%)$, and affection $(1.32 \%)$. In a second study, emotional category ratings were collected with a constrained set of categorical labels that were for the positive subset: awe, excitement, contentment, and amusement. The participants responded on a seven-point scale, with 1 indicating not at all and 7 indicating a great amount, according to the degree to which they felt the word was associated with the specified emotion. Mikels and collaborators chose not to use the label "happy," due its many possible meanings, or its subjectivity. As underlined by Diener, Scollon, and Lucas (2013), happiness is a broad emotional term and nonspecific to a single discrete positive emotion. Results reported by Mikels et al. led them to conclude that the majority of positive images still elicit distinguishable emotions, although many of them are blended, that is to say mixed.

Hence, in summary, the present study strongly develops upon the standard French dimensional norms set, FAN (Monnier \& Syssau, 2014), by importantly providing what is missing from it, the affective categorical norms, and notably at a high resolution. Specifically, for the set of 1031 French words, we provide norms on ten discrete emotion categories, five negative: fear, anger, disgust, sadness, and anxiety and five positive: awe, excitement, contentment, amusement, and serenity. Similar to studies such as by Mikels et al., we also examined two opposing emotions, "anxiety" (negative) already studied by Strauss and Allen (2008) and its positive counterpart "serenity" (corresponding to "peaceful" in Mikels' pilot study).

Major selection criteria for the five positive and five negative emotions chosen for inclusion in FANCat were motivated by aims to develop more fine-grained knowledge about the canonical emotions previously studied in categorical norms. For example, since Stevenson et al. (2007)'s categorical norms: sadness, fear, disgust, and anger have been systematically studied because they have long been recognized as universal basic emotions (Ekman, 1993). Other major selection criteria were motivated by aims to develop a norms set offering a higher resolution of positive emotions (five emotions rather than one), and even negative ones (the addition of anxiety). Specifically, the FANCat project notably went beyond the list of basic emotions that is often limited to five (i.e., four negative emotions and happiness), thus providing an opportunity for more fine-grained information. We remark that some studies have disagreed on which emotions are basic, notably "anxiety" in Strauss and Allen (2008), and so it was included in our study among the four other negative emotions.

In line with the first selection criteria discussed, the five positive emotions selected for FANCat was a decision based on previous research; notably with regard also to experimental studies that have shown these emotions have a specific influence on cognitive processing. For example, four of the five positive emotions included in FANCat: awe, excitement, contentment, and amusement, were notably examined in a number of previous studies (such as Griskevicius, Shiota, \& Neufeld, 2010; Lewis, Haviland-Jones, \& Barrett, 2008; and Mikels et al., 2005). For example in respect to "awe", Griskevicius and colleagues qualified this emotion as "the feeling of being amazed, as though your mind is stretching and your understanding of the universe is expanding; the kind of feeling that freezes you in one spot and makes you want to memorize everything about your experience" (p. 192). Keltner and Haidt (2003) further define awe as a high-arousal, positive emotion felt generally when faced with either beauty, an exceptional aptitude, virtue, an extraordinary phenomenon, or danger. In respect to its influence on cognitive processes, Griskevicius et al. showed that higher awe led to more careful scrutiny of persuasive messages.

Excitement, or "anticipatory enthusiasm", has been qualified as a high-arousal, positive response to novelty and new challenges (Lewis et al., 2008). It is often evoked when a goal is set and perceived as interesting, putting a person into different cognitive and physical dispositions for future reactions to stimuli of the environment. In terms of such cognitive influences, Griskevicius et al. (2010) showed that excitement, in contrast to awe, leads to decreased carefulness or scrutiny in handling incoming persuasive messages.

Contentment is defined by Griskevicius et al. (2010) as a feeling of accomplishment, or when someone's needs have been fulfilled. Previous research has found it can bring an individual to feel united with his/her surroundings; that is, evaluate his/her environment as safe, with a high level of certainty and low state of arousal (Fredrickson, 1998; 
Russell, 1980). Griskevicius et al. showed that contentment had the same kind of effects as excitement on persuasive processing.

Amusement is defined by Griskevicius et al. (2010) as a positive emotion associated with cognitive or social play, humor, and high arousal. Their results also showed that amusement led to less-careful scrutiny of incoming persuasive information. Fredrickson and Branigan (2005) compared the influence of amusement and awe on local and global attentional processing, and on thought-action repertoire. Their results showed that amusement did not lead to more global attentional processing than awe, but did increase participants' thoughtaction repertoires by increasing their urges to be active and outdoors, and, to be playful, social, and elated.

Serenity is characterized by Fredrickson (2013) by low arousal, associated with a feeling calm and tranquility. Serenity has been defined as the absence of anxiety and internal tension, and the ability to enjoy present experiences. It was also studied by Fredrickson and Branigan (2005) as being one of the several positive emotions that broaden the scope of attention.

As such, we find that including additional positive emotions in FANCat provides for interesting/additional research opportunities than the standard 4 negative vs. 1 positive emotion format. As noted by Shiota et al. (2017), and for which we are in agreement, studies examining the influence of positive emotions of cognitive processing are lacking, and we hope that the availability of FANCat leads to more research studies assessing these relationships.

We herein examine FANCat on a number of levels, and control for its validity. We thus first investigated the extent to which interrater reliability is comparable for positive emotional categories versus negative emotional categories; and also do the same for intrarater reliability. We further examined the distribution of pure and mixed words for positive and negative emotional categories, and the relationship between the ratings of each emotion with each other, and with the emotional dimensions (valence and arousal). As in previous studies, we also investigated gender effects.

Moreover, we explored the relationship between the ten discrete emotion ratings and a number of psycholinguistic variables including: word length, frequency, age of acquisition, concreteness, imageability, contextual availability, and sensory experience ratings. To our knowledge, these relationships were previously explored by Hinojosa, Rincón-Pérez, et al. (2016) only for the five emotion model (happiness, anger, sadness, fear, and disgust) and thus in their totality have not been previously explored for the five positive emotions studied here. Finally, we also aimed to validate these norms by providing comparative statistics to other published norms for French (Gobin et al., 2017; Ric et al., 2013), Spanish (Ferré et al., 2017; Hinojosa, Martinez-Garcia, et al., 2016), and English (Stevenson et al., 2007).

\section{Method}

\section{Participants}

Data were collected from a sample of 636 native Frenchspeaking students (127 males, 509 females) from PaulValery Montpellier 3 university. The ages of the participants ranged from 17 to 52 years old $(\mathrm{M}=20.7, \mathrm{SD}=4.6)$. For the most part, the participants came from their first $(n=161)$ or second year $(n=387)$ in psychology. The other part of the sample $(n=93)$ was following their first year in social and economic administration. Informed consent was previously received.

\section{Materials and procedure}

The 1031 French words (962 nouns and 62 adjectives) included in our database correspond to those same words in the French Affective Norms (FAN, Monnier \& Syssau, 2014) set. In this norms set, words were rated on valence and arousal on a nine-point scale. Words with a mean valence score between 1 and 4 were classified as negative, between 4 and 6 as neutral, and between 6 and 9 as positive. This procedure resulted in 131 words being classified as negative ( $7.87 \%$ of the database), 545 words being classified as neutral $(52.86 \%)$, and 355 words being classified as positive (34.43\%). These 1031 words were divided into 17 lists, including 61 or 60 words each. Words from each list were balanced, and alternated on the basis of their valence (i.e., negative word, positive word, negative word, positive word, etc.). Moreover, each list had two versions, where word order was randomly changed. Thus, in total, there were 34 lists, comprised of 22 lists of 61 words and 12 lists of 60 words. Each list contained 21 positive words, 31 to 32 neutral words, and eight negative words.

As part of the approaches to assess the reliability of the ratings in our data sample, in each list we provided a repeat of the same two random words. In addition, like Strauss and Allen (2008), we included a random letter string without any meaning (i.e., itazogue) in every list. All in all, the lists submitted to participants were composed by 63 or 64 words.

The questionnaire took the form of a ten-page, size A-4 packet. Words were centered on the page and printed in a Times New Roman - 14-point bold font. Below each word, we found ten discrete emotions presented in a fixed order alternating positive and negative emotional categories (i.e., awe - émerveillement, fear - peur, contentment - satisfaction, anger - colère, amusement - amusement, disgust - dégoût, serenity - sérénité, sadness - tristesse, excitement - excitation and anxiety - anxiété) to be rated on a five-point ordinal scale from 1 "ne vous évoque pas" (i.e., "does not convey the emotion") to 5 "évoque fortement" (i.e., "strongly convey the emotion"). Moreover, for any word a participant could respond with selecting "je ne connais pas ce mot" ("I do not know this 
word") instead of rating the word. Finally, on the last page, a sentence thanked the participant. The instructions are presented in the Appendix.

Participants performed the study in the experimenter's presence, during one of their courses (in an amphitheater or tutorial class). In order to offer the clearest instructions as possible, we adapted those used in the Ric et al. (2013) study. Therein, the participants had to circle for every word, a rating for each of the ten emotions on a five-point scale that matched the most with their feeling. If participants were not familiar with a word, they had to check the option "je ne connais pas ce mot" (i.e., "I don't know the meaning of this word"). If a participant failed to check this case for the word "itazogue," this flagged them for being excluded from the analysis, since the participant was likely to be responding without reading the question or understanding the instructions. Before beginning the study, we strongly emphasized to the participants a need for sincere responses, and that there were no right or wrong answers.

For good measure, we still, however, performed a light filtering on the data to control for any careless filling of the questionnaire, such as participants that may have marked nearly all words the same, e.g., ranked nearly all words as "1", all words as " 5 ", and so forth. To control for this, we calculated the standard deviation (SD) of each participant's rankings across words, which formed a distribution of standard deviations (636 participants, SDs). We filtered out the participants (48) that were below the 7.5th percentile of this distribution, who had a standard deviation of 0.17 or less. As demonstrated in the Appendix (Fig. 1), the 7.5th percentile provided a suitable threshold, that markedly separated from the next 23 participants who would have constituted the 11th percentile. The FANCat norms database provided as supplementary materials is thus derived from the responses of 588 participants total. The itazogue words (random letter strings without any meaning), which were also used to control for any careless filling of the questionnaire, are not included in the database of 1031 words either.

\section{Supplementary material}

The final database, FANCat norms, is available as supplementary material (https://www.researchgate.net/profile/Arielle $\underline{\text { Syssau)}}$. Column 1 of the database lists the 1031 words in alphabetical order. An English translation is given in column 2 . In columns 3 to 6 , we include the mean rating, and standard deviation of ratings, for Valence and Arousal from Syssau and Monnier (FAN, Affective Norms for French words, 2014). Columns 8 to 23 provide the mean rating (mean) and standard deviation (SD) for each positive emotion: awe, contentment, amusement, serenity, and excitement; and each negative emotion: fear, anger, disgust, sadness, and anxiety. An additional column (column 7) shows the number of ratings for each word

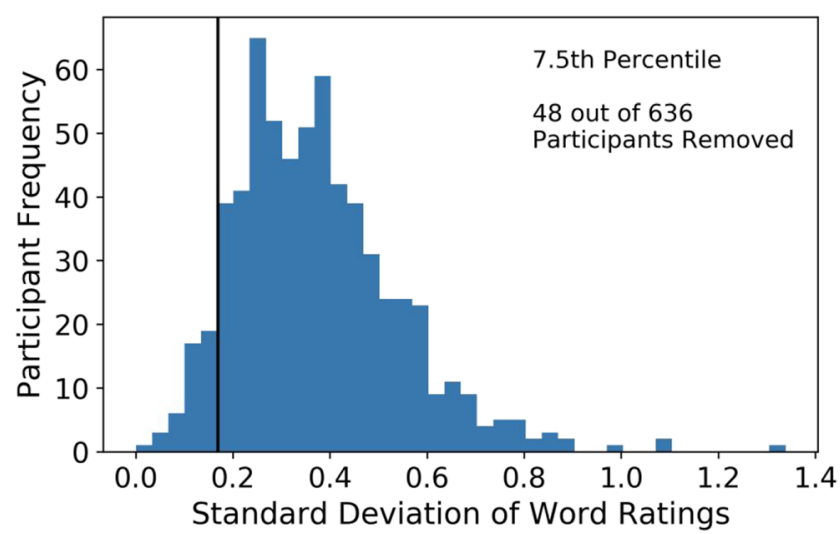

Fig. 1 Distribution of participants based on the standard deviation (SD) of their word ratings. A cut-off based on the SD was utilized to remove participants that may contaminate the data through an insincere filling of the questionnaire, such as by rating most all items at 1.0, or alternatively, most all items at 5.0. The cut-off at the 7.5th percentile resulted in an SD threshold of 0.17 , and provided for an appropriate threshold that separates from the next 23 participants who would constitute the 11th percentile

$(\mathrm{N})$, each word was rated an average of 36 times $(\mathrm{SD}=7.3)$, with a minimum of 26 . In the first sheet, the ratings are from all participants, in the second sheet, from only males, and in the last sheet, from only females. Then the final two sheets of the database respectively provide database information and statistics, and secondly the instructions that were given to the participants.

\section{Results and discussion}

In this section, we proceed to describe the FANCat norms database with descriptive statistics, examine the reliability of the ratings of every emotion, and assess the consistency of the ratings with previous ratings from published norms in French (Gobin et al., 2017; Ric et al., 2013), Spanish (Ferré et al., 2017; Hinojosa, Martinez-Garcia, et al., 2016), and English (Stevenson et al., 2007). We then explore the possibility of gender differences in the ten emotions ratings. Thereafter, we describe the relationships between the ten emotional categories as well as between each emotion and valence and arousal ratings, as well as lexical features (word length, frequency, concreteness, imageability, contextual availability, sensory experience rating [SER]). Finally, we examine the distribution of words among the five positive and five negative emotions.

The database was derived based on the ratings of a final sample of 588 participants (after inclusion criteria). The mean age was $20.65(\mathrm{SD}=3.75)$ with a minimum of 17 and maximum 52 years $(95 \%$ of respondents were between 17 to 25 years old). In terms of gender, $80.32 \%$ of respondents were female and $19.67 \%$ were male. Previous years of education was not a variable collected, however based on the age range and the sample group consisting of first- and second-year 
college students, previous education mainly consisted of high school completion.

\section{Descriptive statistics}

Table 1 shows an overview on the database, with descriptive statistics of the ratings (each word was rated on a scale of 1 to 5) for each of the five positive emotions and each of the five negative emotions. These measures were calculated across the 1031 words surveyed. We also included descriptive statistics in Table 1 for the dimensional measures and psycholinguistic variables of the words. The valence and arousal measures (on scales of 1 to 9), as well as word length and lexical frequency in films (per million) were available for all 1031 words, and were taken from the FAN database (see Monnier \& Syssau, 2014). Of these 1031 words in FANCat, age of acquisition (AoA) ratings were available for 701 words (derived from databases Alario \& Ferrand, 1999; Bonin, 2003; Ferrand et al., 2008; Lachaud, 2007); imageability ratings for 894 words (from Bonin, 2003; Bonin, Méot, Ferrand, \& Roux, 2011; Desrochers \& Thompson, 2009); concreteness ratings for 727 words (Bonin, 2003; Bonin, Méot, \& Bugaiska, 2018); and contextual availability and sensory experience ratings (SER) for 558 words (Bonin et al., 2018).

Table 1 Descriptive statistics for the five positive and five negative emotions ratings, and other affective (valence and arousal) and psycholinguistic indices

\begin{tabular}{lcccc}
\hline Emotion & Mean & SD & Min & Max \\
\hline Awe & 2.26 & 1.52 & 1.00 & 5.00 \\
Contentment & 2.10 & 1.43 & 1.00 & 5.00 \\
Amusement & 2.07 & 1.40 & 1.00 & 5.00 \\
Serenity & 1.90 & 1.34 & 1.00 & 5.00 \\
Excitement & 1.90 & 1.35 & 1.00 & 5.00 \\
Fear & 1.74 & 1.21 & 1.00 & 5.00 \\
Anger & 1.47 & 1.03 & 1.00 & 5.00 \\
Disgust & 1.42 & 0.99 & 1.00 & 5.00 \\
Sadness & 1.46 & 1.02 & 1.00 & 5.00 \\
Anxiety & 1.70 & 1.22 & 1.00 & 5.00 \\
Valence & 5.46 & 1.40 & 1.35 & 8.58 \\
Arousal & 4.29 & 1.08 & 2.14 & 7.86 \\
Length & 6.20 & 1.89 & 2.00 & 12.00 \\
Frequency & 44.22 & 103.13 & 0.00 & 1031.05 \\
Age of acquisition (AoA) & 5.02 & 2.01 & 1.23 & 11.96 \\
Imageability & 5.34 & 1.48 & 1.56 & 6.98 \\
Concreteness & 4.18 & 0.88 & 1.40 & 5.00 \\
Contextual availability & 3.57 & 0.51 & 1.63 & 4.63 \\
Sensory experience rating (SER) & 3.55 & 0.96 & 1.48 & 6.13 \\
\hline
\end{tabular}

\section{Reliability of the ratings}

First, we assessed the interrater reliability of the ratings for each of the 34 versions of the questionnaire with a split-half procedure. Each group that completed a questionnaire version was divided into two equally sized subgroups. Then, Pearson correlations between both subgroups were computed with the Spearman-Brown correction. The results are provided in Fig. 2 , which provides the median, mean, and the 1 st and $3 \mathrm{rd}$ quartiles of the distribution comprised of interrater correlations per emotion. As shown, strong positive correlations were achieved across the ten emotions surveyed. The median correlation values (green lines at notches) ranged between .49 and .62, the mean (green triangles) ranged between .46 and .59 , and the interquartiles ranged between .19 and .33 (disgust being the largest). These strong correlations are consistent with previous studies that only surveyed five emotions per word (e.g., Ferré et al., 2017; Hinojosa, Martinez-Garcia, et al., 2016), but are lower than them by approximately 0.3 units. The higher resolution of emotion assignments in this study (and hence greater distinction), which allows ten emotions surveyed, is a reasonable explanation for the greater variance between respondents. Nonetheless, the inter-rater reliability test shows that each of these ten emotions were strongly correlated per the words surveyed.

Second, as each participant's word list contained two randomly repeated words, intra-rater reliability was assessed by examining the consistency to which participants rated these repeated words on each of the ten emotions. The average absolute difference in the ratings for each emotion are provided in Fig. 3. As can be seen, the average difference for each of the ten emotions was less than 0.5 , with a grand average of 0.39 and average standard deviation of 0.59 . Raters were more consistent on negative emotions than positive emotions $(t=$ $5.42, p<.001)$ by an average of 0.14 units.

\section{External validity}

Our norms shared the greatest number of words in common with the Ferré et al. (2017) discrete norms database with 457 words, then, 258 words with Stevenson et al. (2007), 87 words with Hinojosa, Martinez-Garcia et al. (2016), 78 French words with Gobin et al. (2017), and 15 French words in common with Ric et al. (2013). We examined the validity of our ratings by correlating them with the ratings of those same words in these other norms databases.

As there were no prior ratings on the five positive emotions examined here in previous norms, we first discuss the correlations for negative correlations in FANCat with other French, English, and Spanish norms in Table 2, and then analyze the positive FANCat emotions with happiness in those norms in Table 3. Note that for the negative emotions, anxiety is 


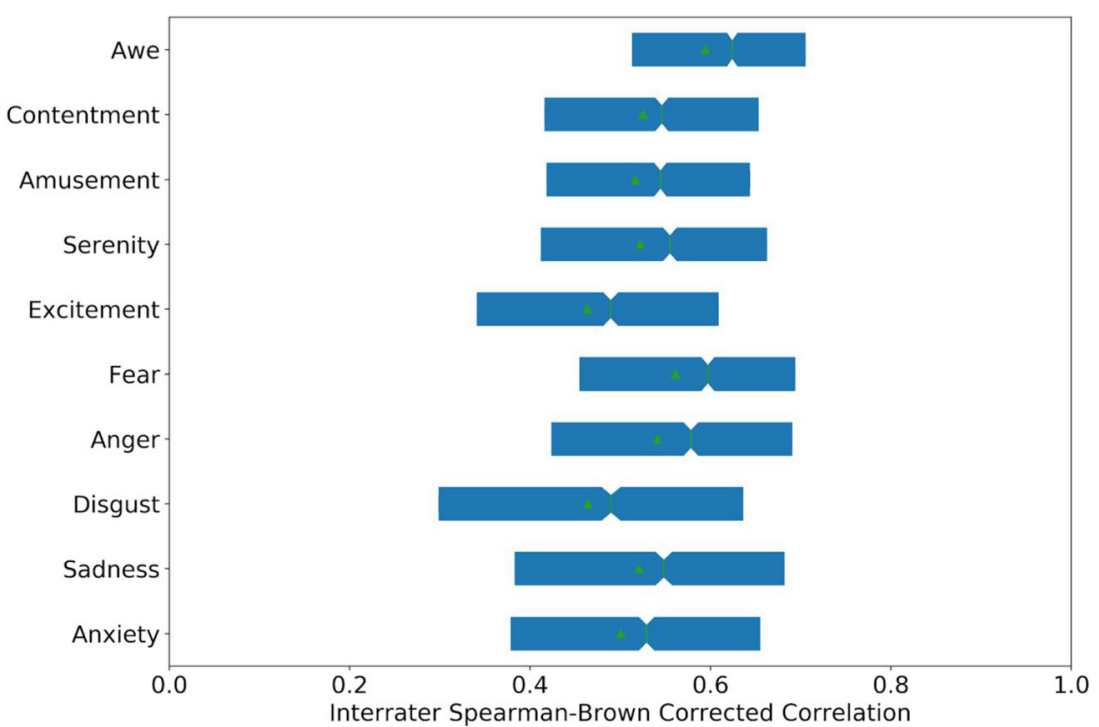

Fig. 2 Mean interrater reliability ratings (Spearman-Brown corrected correlations) for each emotion with interquartile ranges

omitted in the external validity analyses since the other databases do not include ratings for it.

In respect to other French databases, the correlations with Ric et al.'s (2013) database for negative emotions were $r=.76$ for fear $(t(13)=4.22, p<.001), r=.74$ for anger $(t(13)=3.97$, $p=.001), r=.98$ for disgust $(t(13)=17.76, p<.001)$, and $r=$ .77 for sadness $(t(13)=4.35, p<.001)$. Next, correlations with Gobin et al. (2017) were resemblant but lower with $r=.71$ for fear $(t(76)=8.80, p<.001), r=.70$ for anger $(t(76)=8.55, p<$ $.001), r=.65$ for disgust $(t(76)=7.46, p<.001)$, and $r=.72$ for sadness $(t(76)=9.05, p<.001)$.

In respect to English databases, the correlations with Stevenson et al.'s (2007) data were $r=.90$ for fear $(t(256)=$ $33.04, p<.001), r=.89$ for anger $(t(256)=31.23, p<.001), r$ $=.83$ for disgust $(t(256)=23.81, p<.001)$, and $r=.85$ for sadness $(t(256)=25.82, p<.001)$. Lastly, correlations were fairly high in respect to the Spanish databases, in which $r=.88$ for fear $(t(444)=39.48, p<.001), r=.86$ for anger $(t(444)=$ $35.91, p<.001), r=.76$ for disgust $(t(444)=24.92, p<.001)$, and $r=.88$ for sadness $(t(444)=39.48, p<.001)$ for Ferré et al. (2017) and $r=.91$ for fear $(t(84)=20.12, p<.001), r=$ .91 for anger $(t(84)=20.12, p<.001), r=.82$ for disgust $(t(84)$ $=13.13, p<.001)$, and $r=.89$ for sadness $(t(84)=17.89, p<$ .001) for Hinojosa, Martinez-Garcia et al. (2016).

These results demonstrate that the correlations between FANCat and previous norms in the same language (French) are in similar, high magnitude as well as for norms in other languages, such as English and Spanish. Moreover, these results are in line with those reported by previous studies (Briesemeister et al., 2011; Ferré et al., 2017; Hinojosa, Martinez-Garcia, et al., 2016). They also support a continued finding that categorical emotion ratings are generally stable across languages and cultures.

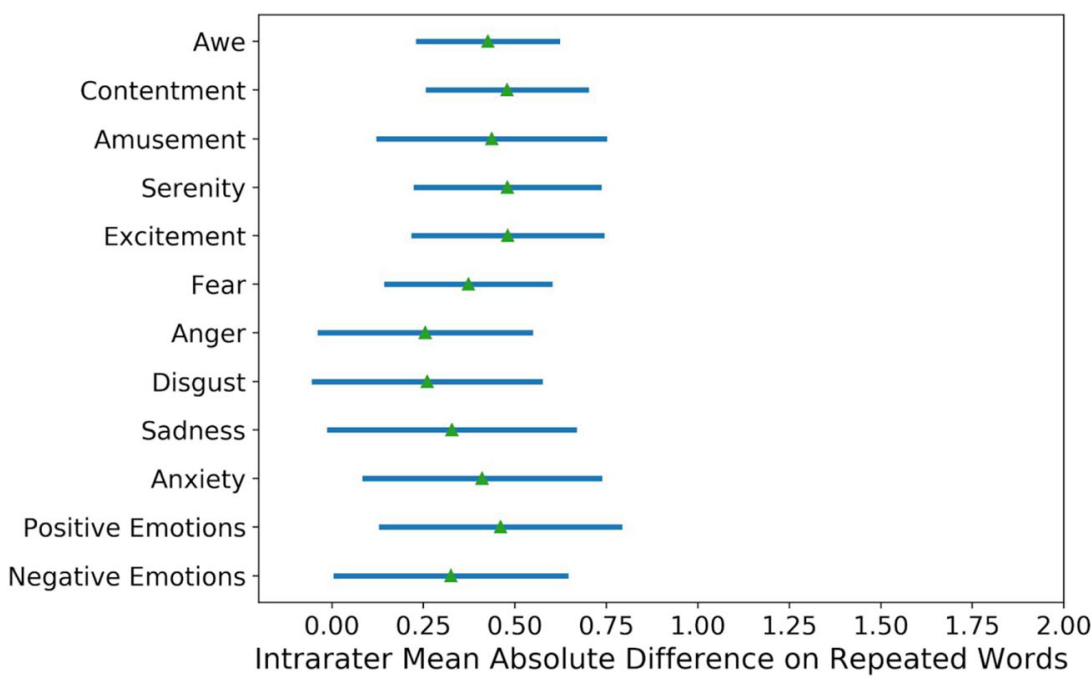

Fig. 3 Mean intra-rater reliability ratings (mean absolute dfference on repeated words) for each emotion with one-half standard deviation interval bars 
Table 2 Pearson correlations between negative emotions from FAN (i.e., anger, sadness, disgust, and fear) and those same emotions from other discrete emotional databases

\begin{tabular}{lllll}
\hline & Fear & Anger & Disgust & Sadness \\
\hline Ferré et al. $^{1}$ & 0.88 & 0.86 & 0.76 & 0.88 \\
Hinojosa, Martinez-Garcia et al. $^{2}$ & 0.91 & 0.91 & 0.82 & 0.89 \\
Gobin et al. $^{3}$ & 0.71 & 0.70 & 0.65 & 0.72 \\
Stevenson et al. $^{4}$ & 0.90 & 0.89 & 0.83 & 0.85 \\
Ric et al. $^{5}$ & 0.76 & 0.74 & 0.98 & 0.77 \\
Mean (SD) & $0.83(0.09)$ & $0.82(0.09)$ & $0.81(0.12)$ & $0.82(0.07)$
\end{tabular}

Note. ${ }^{1} n=456,{ }^{2} n=86,{ }^{3} n=78,{ }^{4} n=258,{ }^{5} n=15$, all $p$ values $\leq .001$

Next, in respect to the positive emotions, as other databases only collected ratings for happiness and no other categories, we analyzed the correlations of the ratings for our five positive emotions with ratings for happiness in the other databases. As in Table 3, each of the five positive emotion categories correlated highly with happiness in the other databases regardless of language (nearly all $r>.55, p<.001$ ). Overall, excitation on average was the most lowly correlated with happiness across databases $(\mathrm{M}=0.65, \mathrm{SD}=0.22)$; and involved the minimum-observed correlation of $r=0.27(t(76)=2.45, p=$ .017) from Gobin et al.'s database (Gobin et al., 2017). Awe and Contentment were the most highly correlated with happiness across the databases with very similar means $(\mathrm{M}=0.81$, $\mathrm{SD}=0.10$ and $\mathrm{M}=0.80, \mathrm{SD}=0.09$ respectively).

\section{Gender differences}

The interaction between gender and emotion category ratings was assessed by a Friedman test, respectively for the positive and negative emotion categories. The by-word average rating differences between males and females were significantly different across the five positive emotion categories $\left(\chi^{2}=29.81\right.$, $p<.001)$, and to a greater extent in the five negative emotion categories $\left(\chi^{2}=133.47, p<.001\right)$. We next assess the individual comparisons with pairwise $t$ tests.
By gender, the mean and standard deviation of ratings for each of the ten discrete emotions are provided in Table 4. On average, male participants overall rated words significantly higher than females for serenity (Welch $t(10819)=2.69, p=$ $.007)$, anger $(t(10810)=5.39, p<.001)$, disgust $(t(10808)=$ $3.95, p<.001)$, and sadness $(t(10815)=2.50, p=.013)$. On the contrary, women rated words significantly higher than men for fear $(t(10820)=-2.88, p=.004)$ and anxiety $(t(10819)=-3.59, p<.001)$. No gender differences were found in ratings for Awe $(t(10813)=-1.35, p=.18)$, contentment $(t(10807)=0.13, p=.90)$, amusement $(t(10815)=1.20$, $p=.23)$, and excitement $(t(10815)=1.31, p=.19)$. On the ten emotional categories, we did not observe significant gender differences for four positive emotions (awe, contentment, amusement, and excitement) and only one positive emotion, serenity, was rated higher by male participants than by female participants. For the five negative emotions examined here, women rated words higher than man for fear and anxiety and males rated words significantly higher than females for anger, disgust, and sadness. In previous studies, gender differences were different between studies for negative emotions. For example, Stevenson et al. (2007) reported that females gave higher ratings than males for all negative emotions whereas Hinojosa, Martinez-Garcia et al. (2016) reported the reverse pattern of results for anger and fear. In view of these contradictory results from one study to another, we

Table 3 Pearson correlations between the positive emotions from FAN (i.e., awe, contentment, amusement, serenity, and excitation) and happiness from others emotional databases

\begin{tabular}{|c|c|c|c|c|c|}
\hline & Awe & Contentment & Amusement & Serenity & Excitation \\
\hline Ferré et al. ${ }^{1}$ & 0.78 & 0.81 & 0.71 & 0.73 & 0.69 \\
\hline $\begin{array}{l}\text { Hinojosa, Martinez- } \\
\text { Garcia et al. }{ }^{2}\end{array}$ & 0.91 & 0.91 & 0.77 & 0.83 & 0.75 \\
\hline Gobin et al. $^{3}$ & 0.65 & 0.67 & 0.56 & 0.65 & $0.27 *$ \\
\hline Stevenson et al. ${ }^{4}$ & 0.83 & 0.83 & 0.70 & 0.73 & 0.69 \\
\hline Ric et al. ${ }^{5}$ & 0.88 & 0.77 & 0.77 & $0.56^{*}$ & 0.86 \\
\hline Mean (SD) & $0.81(0.10)$ & $0.80(0.09)$ & $0.70(0.09)$ & $0.70(0.10)$ & $0.65(0.22)$ \\
\hline
\end{tabular}

Note. ${ }^{1} n=456,{ }^{2} n=86,{ }^{3} n=78,{ }^{4} n=258,{ }^{5} n=15$, all $p$ values $<.001$ except those specified; $* p<.05$ 
Table 4 Means and standard deviations of the ratings in the ten discrete emotions, by gender

\begin{tabular}{lllll}
\hline Emotion & Mean male & Mean female & SD male & SD female \\
\hline Awe & 2.34 & 2.37 & 1.51 & 1.55 \\
Contentment & 2.19 & 2.19 & 1.43 & 1.46 \\
Amusement & 2.18 & 2.15 & 1.41 & 1.42 \\
Serenity & 2.01 & 1.96 & 1.36 & 1.38 \\
Excitement & 2.00 & 1.97 & 1.36 & 1.38 \\
Fear & 1.77 & 1.82 & 1.20 & 1.26 \\
Anger & 1.57 & 1.50 & 1.09 & 1.06 \\
Disgust & 1.50 & 1.45 & 1.04 & 1.02 \\
Sadness & 1.53 & 1.50 & 1.05 & 1.05 \\
Anxiety & 1.72 & 1.78 & 1.20 & 1.26 \\
\hline
\end{tabular}

believe that differences in gender emotional judgment cannot lead to any conclusions. However, these differences should be reported to the researcher for the selection of words in relation to the study population.

Next, at the by-word average level, the Pearson correlations between males and females for each emotion category were $r$ $=.82$ for awe, $r=.76$ for contentment, $r=.77$ for amusement, $r=.77$ for serenity, $r=.73$ for excitement, $r=.08$ for fear, $r=$ .79 for anger, $r=.75$ for disgust, $r=.79$ for sadness, and $r=$ .74 for anxiety. These correlations were all significant (all $p$ values $<.001$ ) and positive, as had previously been reported by Hinojosa, Martinez-Garcia et al. (2016) and Ferré et al. (2017) in their analyses of gender effects in the five-scale spectrum emotion ratings (happiness, anger, sadness, fear, disgust).

Also, at the by-word average level, we explored for significant magnitude differences in word ratings between genders.
The results indeed revealed large differences for some words between genders. For example, the word nid ("nest") was rated higher in awe by women than by men (with a difference of 2.26 points). On the contrary, men rated the word cicatrice ("scar") higher in contentment than women did (a difference of 1.44 points). Overall, with a significance level of 0.05 , $10.77 \%$ of words differed significantly between the genders in awe ratings, $9.89 \%$ in contentment, $8.54 \%$ in amusement, $8.83 \%$ in serenity, $12.80 \%$ in excitement, $10.48 \%$ in fear, $5.82 \%$ in anger, $7.57 \%$ in disgust, $8.34 \%$ for sadness, and $13.29 \%$ in anxiety. Thus, only a limited number of words (9.63\% on average, per category) showed gender differences in discrete-emotion ratings, and these percentages are similar to the previous studies discussed that evaluated words by gender in the five-scale emotion spectrum (Ferré et al., 2017; Stevenson et al., 2007).

In summary, these results suggest that although there is high consistency between the ratings of males and females, some gender differences are existent. However, the magnitude of these differences is quite low. For example, in the average overall emotion ratings by gender in Table 4 , the differences ranged only from $<0.01$ to 0.07 points, and the by-word mean differences per emotion only ranged from 0.29 to 0.47 . Though caution should be taken in drawing any firm conclusions from these gender-based analyses, considering the overrepresentation of females in the sample (only $24.6 \%$ of the respondents were males).

\section{Relationship between discrete emotions and affective and psycholinguistic dimensions}

We also analyzed the pattern of correlations between the ten discrete emotions, and the affective (see Table 5) and

Table 5 Number and percentage of words belonging to each emotional category with average ratings of these words, and valence and arousal means and standard deviations

\begin{tabular}{|c|c|c|c|c|c|c|c|c|}
\hline Emotion & $N$ & $\%$ & Mean & $\mathrm{SD}$ & Valence mean & Valence SD & Arousal mean & Arousal SD \\
\hline Awe & 162 & 15.71 & 3.82 & 0.43 & 6.67 & 0.77 & 4.84 & 0.95 \\
\hline Contentment & 72 & 6.98 & 3.64 & 0.41 & 7.00 & 0.72 & 5.07 & 0.95 \\
\hline Amusement & 71 & 6.89 & 3.71 & 0.52 & 6.29 & 0.98 & 4.86 & 1.08 \\
\hline Serenity & 40 & 3.88 & 3.79 & 0.45 & 6.84 & 0.89 & 3.94 & 0.89 \\
\hline Excitement & 19 & 1.84 & 3.74 & 0.51 & 6.86 & 0.74 & 6.24 & 0.74 \\
\hline Fear & 49 & 4.75 & 3.73 & 0.44 & 3.38 & 1.16 & 5.34 & 0.86 \\
\hline Anger & 17 & 1.65 & 4.07 & 0.54 & 2.34 & 0.88 & 6.16 & 1.04 \\
\hline Disgust & 11 & 1.07 & 3.63 & 0.48 & 3.02 & 0.92 & 4.52 & 0.95 \\
\hline Sadness & 12 & 1.16 & 4.13 & 0.53 & 2.26 & 0.41 & 4.96 & 0.78 \\
\hline Anxiety & 16 & 1.55 & 3.56 & 0.56 & 3.94 & 1.45 & 4.90 & 0.98 \\
\hline Neutral & 562 & 54.51 & - & - & 5.89 & 1.76 & 4.96 & 1.06 \\
\hline Total & 1031 & 100.00 & & & & & & \\
\hline
\end{tabular}


psycholinguistic dimensions (including valence and arousal, length, and frequency from the FAN database, Monnier \& Syssau, 2014, among others). The correlation matrix is presented in Fig. 4. As can be seen, two principal clusters are formed with positive correlations, which is between the five positive emotions and between the five negative emotions (in light green). These correlations ranged between $r=.5$ to $r=.8$. In the positive emotions, awe and excitement were the most correlated $(r=.81)$ and amusement and excitement $(r=.82)$. In the negative emotions, fear and anxiety were the most correlated $(r=.93)$. On average, the most negatively correlated emotions with the positive emotions was disgust $(r=-.33)$ and in second, anger $(r=-.24)$. Note that after Bonferroni correction, $p<.001$ for $r \geq .16$ (and when $N=1031$ words).

Next, valence was correlated positively with the positive emotions, $r=.62$ to $r=.81$, and negatively with the negative emotions with $r=-.44$ to $r=-.63$. Among the positive emotions, the weakest correlation with valence was for excitement $r=.62$, that is perhaps the more ambivalent positive emotion studied here. Excitement is an emotion felt when we anticipated a result or an event. This expectation can lead to feeling hope but also anxiety. Moreover, excitement was the only positive emotion that was positively correlated with fear and anxiety. Values of arousal were correlated positively with positive and negative emotions similarly with $r=.23$ to $r$ $=.47$, except for excitement which outstood the rest with $r=$ .65. For each emotion cluster, the lowest values of arousal occurred for emotions serenity, disgust, and sadness, while the highest values of arousal occurred for emotions awe, excitement, fear, and anxiety. A number of these present findings are comparable to those reported by Ferré et al. (2017), Hinojosa, Martinez-Garcia et al. (2016), and Briesemeister et al. (2011). Indeed, in these previous studies, disgust was the negative emotion whose correlation with arousal was the weakest relative to others negative emotions. All in all, the heterogeneity of the relationship between each emotional category and the affective dimensions underlie the distinctiveness and the complementarity of the information provided by the dimensional approach and the categorical approach, and what is true for negative emotions is just as true for the different positive emotions.

We also analyzed the correlation patterns between the discrete emotion ratings and their lexical and semantic variables (see Fig. 4). Word length and frequency did not exhibit notable correlations with either positive or negative emotions ( $r$ values ranged from .0 to .22 , though

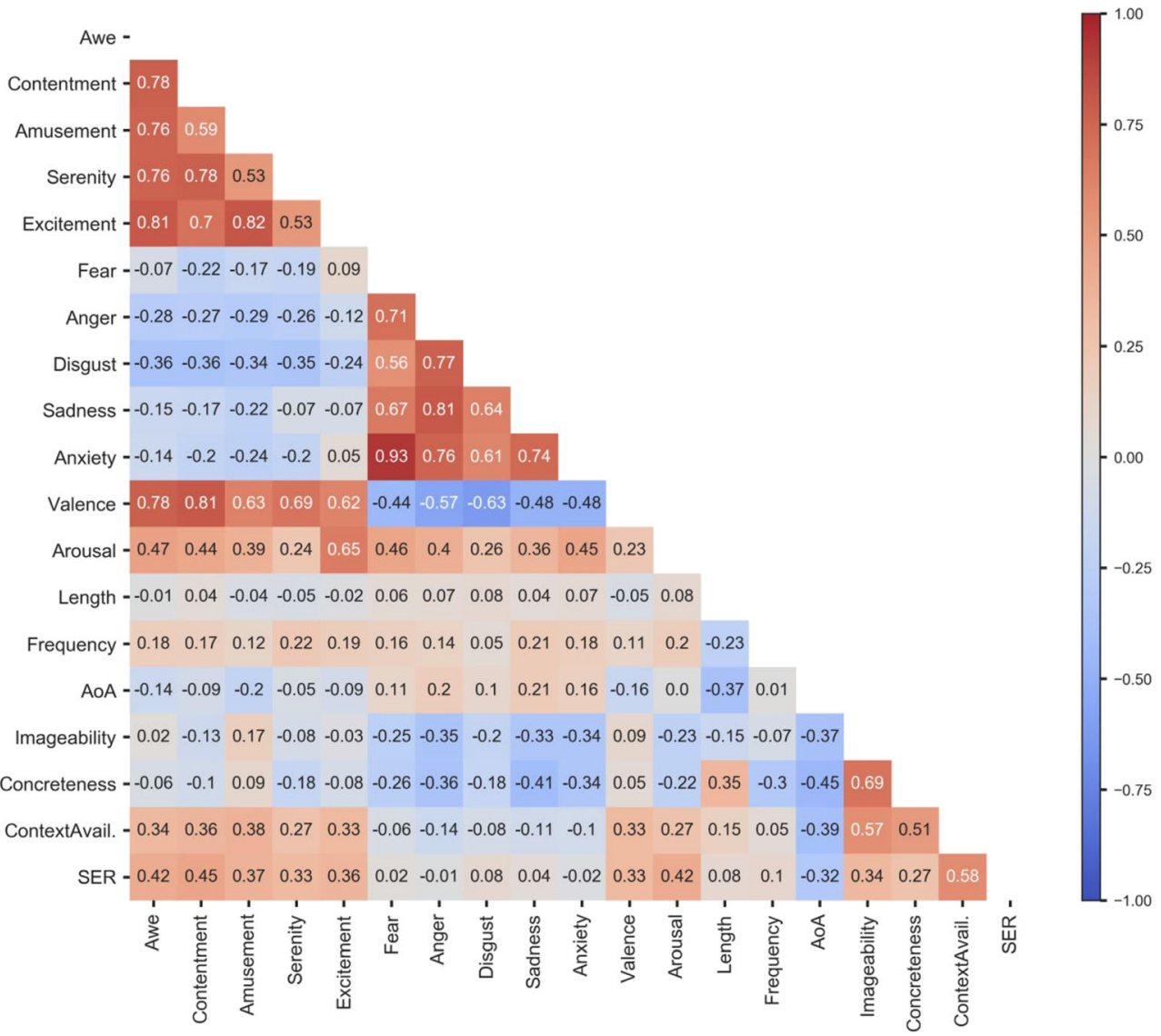

Fig. 4 Correlation matrix with color map of the by-word, mean value $(N$ $=1031$ ) emotion ratings for each of the ten emotions and psycholinguistic variables (note SER $=$ sensory experience rating). Significance ( $p$ values)

calculated with Bonferroni correction leads to $p<.001$ for $r \geq .16, p<.01$ for $r \geq .14$, and $p<.05$ for $r \geq .12$ for correlations with $N=1031$ 
serenity was most correlated with frequency). We replicated previously found weak correlations between word length and fear, anger, and sadness emotions; for example, Hinojosa, Martinez-Garcia et al. (2016) reported $r$ values from .11 to .12. However, we did not find a negative correlation between frequency and negative emotions in French words, contrary to in Spanish words reported by Hinojosa, Martinez-Garcia et al. (2016); further study may be required to determine if there is a language dependency of this effect. Finally, a weak correlation was observed between frequency and arousal $(r=.20)$.

In respect to AoA, Hinojosa, Rincón-Pérez et al. (2016) reported a negative correlation with the only positive emotion studied (happiness), while positive correlations were observed for angry, sad, fearful and disgust words. Herein FANCat, the same correlation trend was found for AoA: negative correlations were between -.05 and -.20 occurred for the five positive emotions (minimum value, -.05 , for serenity), while positive correlations occurred between .10 and .21 for the five negative emotions.

Next, in line with Hinojosa, Rincón-Pérez et al. (2016), we also explored correlations with sensory experience rating (SER). Taking into account SER, or the embodied semantic perspective of emotional words (Kousta, Vigliocco, Vinson, Andrews, \& Del Campo, 2011), has gained increased interest in recent research. SER is considered to be a broader or stronger cue than imageability or concreteness as it covers the entire repertory of sensory experience, not only visual. For example, SER has been found to be a significant predictor of lexical decision times (Bonin, Méot, Ferrand, \& Bugaiska, 2015).

In respect to SER, Hinojosa, Rincón-Pérez et al. (2016) found positive correlations among all five discrete emotions, concluding that words associated with more vivid sensorial attributes are also those rated with higher scores (for happiness, anger, sadness, fear, and disgust). In our data, a comparable but notably different pattern was produced. We indeed found meaningful correlations between SER and the five positive emotions (awe, contentment, amusement, serenity, and excitement) for which $r$ values ranged between .33 and .45 . However, in contrast, correlation values were close to 0 for the negative emotions, ranging between $r=-.02$ and .08 . As a result, we can affirm that positive words generate a rich multimodal sensory experience and not only a visual one. Because SER refers to all sensory information beyond only imageability (e.g., gustatory, olfactory, and auditory information) and because SER has strong and complex relationships with concreteness (Bonin et al., 2018), we also explored the correlations of concreteness, imagery, and contextual availability.

Imageability and concreteness were markedly correlated negatively with the negative emotions $(r$ from -.20 to -.34 and $r$ from -.18 to -.41 , respectively), while these correlations were close to 0 for positive emotions. Consistent with our SER results, this result confirms that FANCat database negative words are poor in evoking sensory information, and that positive words evoke more diverse sensory information than just visual information.

The opposite trend occurred in respect to contextual availability (ContextAvail.) and SER ( $r=.27$ to .38 and $r=.33$ to .42 , respectively, for positive emotions). Consistent with these results, imageability and concreteness were negatively correlated with arousal $(r=-.22$ and $r=-.23)$ and ContextAvail. and SER were positively correlated with arousal $(r=.27$ and $r$ $=.42$ ). Moreover, ContextAvail. and SER were positively correlated with valence $(r=.33$ and $r=.33)$.

In line with previous findings (e.g., Hinojosa, RincónPérez et al., 2016), these results support claims to take into account psycholinguistic variables for appropriate word selection. Furthermore, these results highlight the importance of analyzing SER to capture a general embodied meaning of emotional words. For example, SER was more associated with the positive emotions, and consistent with previous findings, the mean ratings for the positive emotions were also higher than the negative emotions. This also appeared respected within the positive emotions themselves: awe and contentment, having higher correlations with SER ( $r=.45$ and .43$)$, also exhibited higher mean ratings than the other positive emotions. Lower SER ratings for negative emotions may suggest avoidance in their experience.

\section{Distribution of the words among the ten discrete emotions}

Following Hinojosa, Martinez-Garcia et al. (2016) and Ferré et al. (2017), we classified the ratings into two groups, yet with a higher classification threshold (3.0 instead of 2.5 as in Stadthagen-González et al., 2018); the higher threshold was used to better distinguish belonging among the ten emotions. These groups were defined as: low level (values lower than or equal to 3.0) and high level (values higher than 3.0). Words with high values in more than one discrete emotion were considered as belonging to the emotion with the highest score. Words with low values in the ten emotions were considered neutral words. Neutral words category includes 562 words or $54.51 \%$ of the dataset. This percentage is lower than that (80.07\%) reported by Stadthagen-González et al. (2018) while we used the same categorization criteria. This difference may suggest that the additional positive emotion categories in our study allowed participants to categorize words into categories that were not proposed in previous studies. For example, the word "sound" was neutral in Stadthagen-González et al. (2018) and its mean rating for happiness was less than 3 (M $=2.45, \mathrm{SD}=1.36$ ) and less than 2 for negative emotions, whereas in FANCat which allows greater specificity, its mean rating was greater than 3 for awe $(\mathrm{M}=3.67, \mathrm{SD}=1.76)$, 
contentment $(\mathrm{M}=3.16, \mathrm{SD}=1.61)$, amusement $(\mathrm{M}=3.24$, $\mathrm{SD}=1.33)$, and serenity $(\mathrm{M}=3.12, \mathrm{SD}=2.06)$.

Previous studies only allowed for one positive emotion to be considered: happiness, and the remaining four emotions were negative (anger, sadness, fear, disgust), as in Ferré et al. (2017) and Hinojosa, Martinez-Garcia et al. (2016). The result is a large majority of those words (e.g., near $32.3 \%$ and $35.1 \%$, respectively) were rated as happy words. Our study corresponds in that the sum of words classified in our five positive emotion categories leads to $35.3 \%$ of words. The majority of these positive words were ranked in awe $(15.71 \%)$ and subsequently contentment $(6.98 \%)$ and amusement $(6.89 \%)$. In this way, this study shows the extra information offered by surveying ten emotion options. In regard to the negative emotions, our study added anxiety. The results correspond to the previous studies in fear still being in highest proportion, though generally the other negative emotions are evenly distributed with anxiety added. This consistency with previous studies regarding negative emotions regardless of the number of options (i.e., 10 or 6 ) show that the increase of number of emotions studied did not alter their assessment. With respect to Stadthagen-González et al. (2018), we have fewer words that fall into the negative emotion categories. In our database, the majority of these negative words were ranked in fear $(4.75 \%)$ and subsequently anger $(1.65 \%)$, anxiety $(1.55 \%)$, and sadness $(1.16 \%)$. In the study of StadthagenGonzález et al., a different order was observed with the majority of negative words in sadness $(5.20 \%)$, and subsequently anger $(4.72 \%)$ and fear $(3.63 \%)$. The least-represented negative emotion category in these two studies using the same classification criteria is disgust (1.07\% in FANCat and $2.65 \%$ in Stadthagen-González et al.). As Monnier and Syssau (2014) have indicated, the FAN database contains more words that evoke positive emotions than negative ones.

Table 6 Numbers and percentages of "pure words" with high values in one emotional category and low values in all other categories

\begin{tabular}{llllll}
\hline Emotion & Example & Translation & $N$ & Total (\%) & Category (\%) \\
\hline Awe & génie & genius & 39 & 3.78 & 24.07 \\
Contentment & vertu & virtue & 25 & 2.42 & 34.72 \\
Amusement & balançoire & swing & 31 & 3.01 & 43.66 \\
Serenity & silence & silence & 7 & 0.68 & 17.50 \\
Excitement & début & start & 2 & 0.19 & 10.53 \\
Fear & couteau & knife & 10 & 0.97 & 20.41 \\
Anger & supercherie & fraud & 2 & 0.19 & 11.76 \\
Disgust & cigarette & cigarette & 8 & 0.78 & 72.73 \\
Sadness & pitié & pity & 2 & 0.19 & 16.67 \\
Anxiety & santé & health & 6 & 0.58 & 37.50 \\
Neutral & temps & times & 562 & 54.51 & 100.00 \\
Total & & & 694 & 67.31 & \\
\hline
\end{tabular}

An average difference in valence and in arousal between the FAN database presented here and that of StadthagenGonzález et al. can be seen in the descriptive statistics of the two databases (see Table 1). The FAN database resulted in a higher average valence of 5.46 compared to 5.18 of Stadthagen-González et al. (Welch $t(1183)=5.80, p<.001)$ and a lower arousal of 4.29 compared to 5.29 (Welch $t(1158)$ $=-29.15, p<.001)$. These differences might be attributed to language differences or the stimulus sets themselves.

So far, we have classified words based on their highest emotion rating. Next, we examine the data set for "pure" words, which are defined as words with high values in only one discrete emotion. Table 6 shows the distribution of these words among the discrete emotion categories.

As can be seen in Table 6, 67.31\% of the stimuli in the dataset can be considered "pure" words, either because they were mainly assigned to a single emotion $(12.8 \%)$ or because they were neutral with respect to the ten categories $(54.51 \%)$. Words denoting awe $(3.78 \%)$, contentment $(2.42 \%)$, and amusement (3.01\%) were the largest sets. Of the "pure" emotion word set, positive emotions were more highly represented than negative emotions ( $79 \%$ positive versus $21 \%$ negative). In our correlation analyses, we found high correlations between emotions ratings and SER for all of the positive emotions, while correlations were close to 0 for the negative emotions. It is possible that the higher sensorial richness of positive words, leading to a more distinct internal representation, facilitates their evaluation and hence classification into a single positive emotional category. Given the novelty of this finding, further studies are needed to confirm this proposed interpretation.

Finally, as related to our difference in surveying ten discrete emotions rather than 5 , about $30 \%$ fewer emotion words can be found to be considered pure (e.g., than in Ferré et al., 2017), when one considers these other emotions. We can also answer a question, left open by Ferré et al. about the purity of the emotional category of happiness. Ferré et al. wrote that before drawing conclusions on this category, which was the only positive emotion proposed in their study, it was necessary to conduct complementary studies with other categories of positive emotions. Results reported here confirm that pure words are mostly present in the categories of positive emotions and in the disgust category.

To explore the question of whether there was a constant pattern to negative and positive emotions separately, we conducted an additional analysis using the Proxal procedure (Busing et al., 1997) with a multidimensional scaling analysis (MDS). We projected the Euclidean distances between positive words in a three-dimensional space (Fig. 5), as well as for negative words (Fig. 6). Hence, neutral words were omitted in each MDS analysis (or any cases of positive-classified words with a rating of 3.0 or higher in a negative emotion, and vice versa). After applying the procedure, the Kruskal stress values 

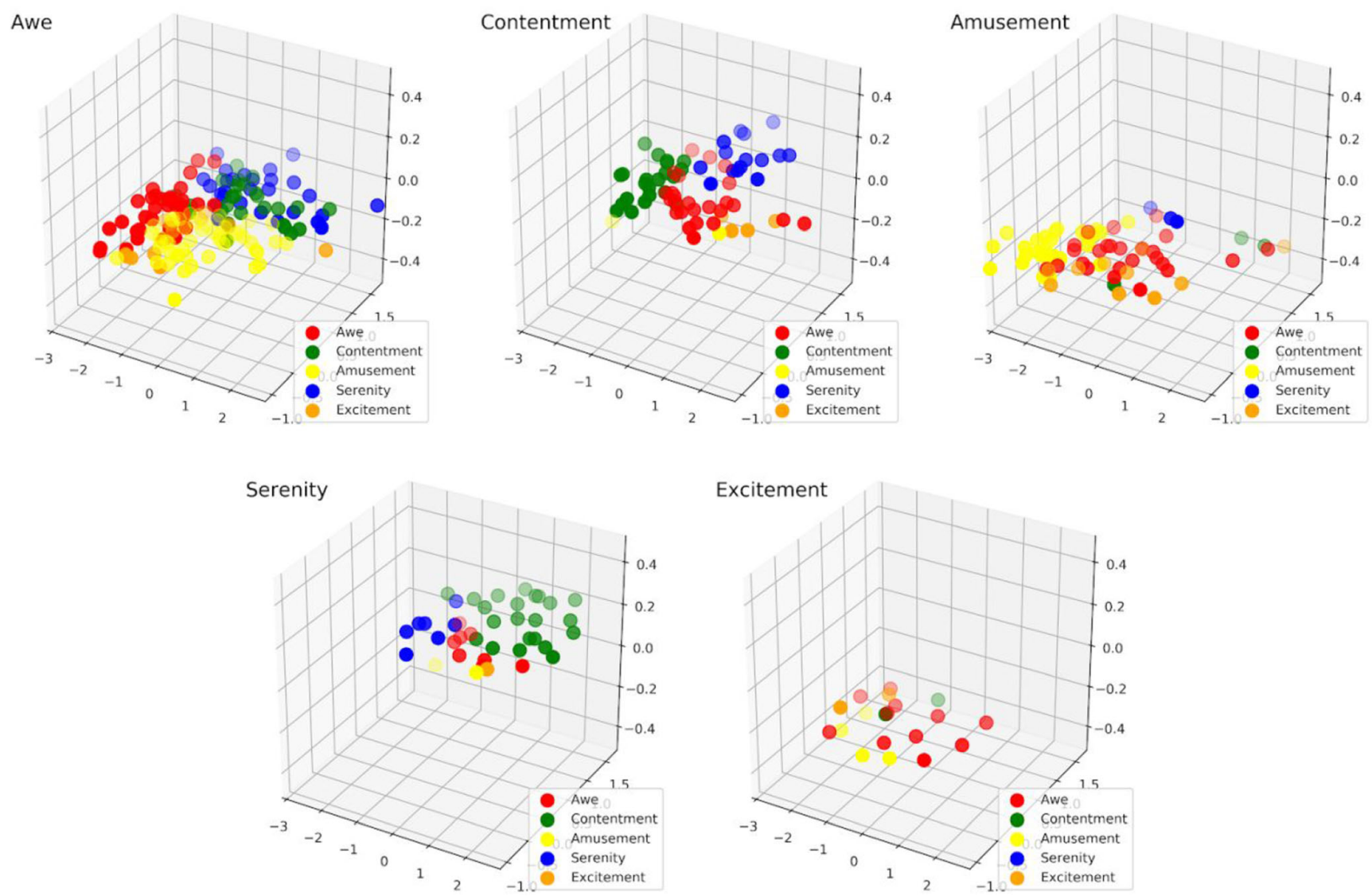

Fig. 5 Multidimensional scaling for the positive emotion words

of the resulting 3D spaces for positive and negative emotions were respectively 0.014 and 0.043 , which are values supportive of appropriate projections (see Kruskal \& Wish, 1978; Sturrock \& Rocha, 2000)

Beginning with the positive MDS analysis in Fig. 5, and with the emotion awe (upper-left plot), a number of pure awe words are available (in red), and non-pure awe words principally have significant properties of amusement (yellow), serenity (blue), and contentment (green). The MDS analysis shows that these non-pure awe words with strong serenity or excitement qualities are more similar to one another (the blue/ green clusters nearly overlapping) than awe words with amusement qualities (yellow). In the next plot, beside pure contentment words (green), non-pure contentment words also showed two distinct groups, with serenity (blue) and awe (red). In the third plot, the cluster of pure amusement words is shown in yellow, non-pure amusement words mostly had awe and excitement qualities, which formed a similar cluster (awe being the closest to pure amusement words). In the fourth plot, we see that pure serenity words (blue) are few in proportion to the non-pure serenity words, which are most strongly second-highest rated in contentment (green), and occupy a wider area of diversity. Finally, in the fifth plot, there are few pure excitement words and most non-pure excitement words are charged with awe.
With regard to the negative emotions MDS in Fig. 6, and starting in the first plot with fear words, fear had the largest amount of words than the other negative emotions. Pure fear words (in red) are low in proportion however (10), to non-pure fear words (49), which have high qualities in anxiety. In the second plot, anger has only two pure words (green) and instead most are non-pure words (17), which have high properties in disgust. In the third plot, we see how disgust has the highest number of pure words (yellow) among the negative discrete emotions ( $72 \%$ of the category), and only three nonpure words. In the fourth plot, sadness only has a few pure words (blue), like anger, and most non-pure sadness words are linked to properties of anxiety (orange). Finally, in the fifth plot, two distinct clusters are shown between pure anxiety words (orange) and non-pure anxiety words, which are high in fear (red).

These results suggest that certain categories of emotions have close links between them, such as fear and anxiety, or serenity and contentment. In this way, future studies that assess the cognitive or emotional processing of words, or how words may indirectly express emotions (e.g., StadthagenGonzález et al., 2018), will need to better consider the emotional profile of words in order to precisely understand these processes. We hypothesize that "mixed words," which refer to several discrete emotions and therefore involve several 

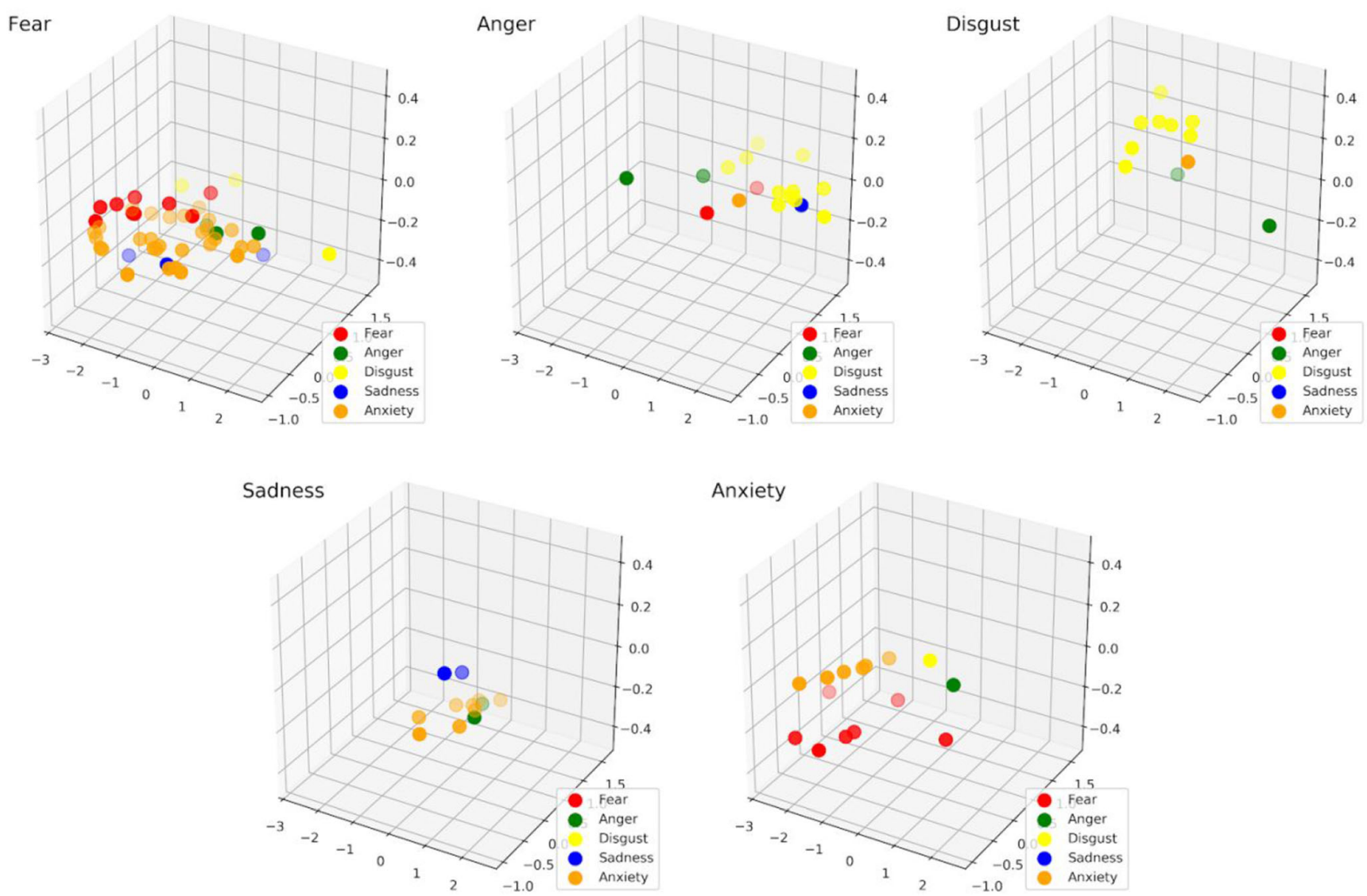

Fig. 6 Multidimensional scaling for the negative emotion words

emotional systems, will not be cognitively processed in the same way as "pure words" that evoke only one emotion. Moreover, before drawing such conclusions on mixed words in future studies, it would be interesting to consider to what extent the different emotions evoked by various mixed words can be generalized to other languages and populations.

\section{Conclusions}

The present norms dataset, FANCat, expands on the initial FAN norms of Monnier and Syssau (2014) by providing comprehensive ratings of 1031 French words along ten discrete emotions, five negative (fear, anger, disgust, sadness and anxiety) and five positive (awe, excitement, contentment, amusement and serenity. A notable, original contribution of the current study, relative to previous ones, is to have introduced (and assessed) five different categories of positive emotions rather than one or two. As a result, we were also able to measure whether the validity of judgements for positive emotional categories is comparable to negative emotional categories. The ratings presented here showed a high degree of inter-rater agreement for both positive and negative emotional categories. Furthermore, the ratings obtained for emotional categories resulted in high correlations with previous norm databases in French (Gobin et al., 2017; Ric et al., 2013), Spanish (Ferré et al., 2017; Hinojosa, Martinez-Garcia, et al., 2016), and English (Stevenson et al., 2007). We can conclude that FANCat, even its higher resolution of emotion assignments and hence greater distinction, allowing ten emotions surveyed, has good reliability and external validity.

With regard to the positive emotion categories, the majority of the positive words (35.3\%) were ranked in awe (15.71\%) and subsequently contentment (6.98\%), amusement (6.89\%), serenity (3.88\%), and excitement (1.84\%). Consequently, this study demonstrates that the extra information provided by surveying ten emotion options, and specifically five positive emotion options, strongly confirms the importance that positive emotions should be distinguished beyond only happiness (Shiota et al., 2017). It was indeed found that words evoking positive emotions, just like words evoking negative emotions, can either be "pure" (mainly assigned to a single emotion), or "mixed" (assigned to at least two emotions). In fact, of the "pure" emotion word set, positive emotions were more highly represented than negative emotions (79\% positive versus $21 \%$ negative). Pure positive words were more frequent in the categories awe, contentment, and amusement than in the other positive and negative emotional categories. Concerning 
"mixed" positive emotion words, our MDS analyses demonstrated that positive emotions, such as awe and serenity, can be simultaneously evoked by a single word.

These results, showing for a higher proportion of pure positive words and mixed negative words, invites further research. This finding can be used in service of resolving discrepancies in the literature regarding the visual recognition of positive versus negative words. Specifically, studies have yielded a sure facilitation effect for positive word recognition (e.g., Syssau \& Laxén, 2012), but have yielded notable discrepancies as to whether there is an advantage or a disadvantage for negative words (e.g., Larsen, Mercer, Balota, \& Strube, 2008). Would the benefit for positive words come from their quality of being pure, and could the discrepancies around negative words be explained by a lack of control over the pure or mixed quality of the negative emotions evoked by those negative words?

We hope that by providing a new large, comprehensive emotional categorical norms database, that this encourages the study of emotion and language in line with hierarchical emotion theory (Panksepp, 1998, 2007; Panksepp \& Biven, 2012), which accents the importance of analyzing both the dimensional and categorical aspects of words. We also encourage future studies to consider that positive emotion words may have much more specificity and diversity, beyond evoking only happiness.

\section{Appendix}

The following texts are the instructions given to the participants in French and their corresponding English Translation

\section{Instructions}

Nous allons vous présenter une liste de mots. Pour chacun de ces mots, nous vous demandons d'indiquer dans quelle mesure ils évoquent pour vous les 10 émotions suivantes : l'émerveillement, la peur, la satisfaction, la colère, l'amusement, le dégoût, la sérénité, la tristesse, l'excitation et l'anxiété.

Les émotions ont été définies oralement par un des expérimentateurs comme suit :

L'émerveillement peut être défini comme un état associé à l'étonnement et à la contemplation. Lorsqu'un individu ressent cette émotion, son esprit s'enrichit et sa compréhension de l'Univers se développe. C'est une émotion qui immobilise et donne envie d'explorer tous les détails de l'expérience vécue.

L'amusement est une émotion associée au jeu et à l'humour, elle apparaît généralement quand un individu souhaite rire et plaisanter avec les autres.

L'excitation est une réponse positive donnée face à la nouveauté et aux nouveaux défis. Elle apparaît quand un objectif est perçu comme intéressant et place les individus dans les dispositions adéquates pour réagir aux différents stimuli de l'environnement.

La satisfaction entraîne un sentiment d'accomplissement. Elle apparaît quand les besoins d'une personne sont accomplis. Elle amène l'individu à se sentir uni avec ce qui l'entoure et lui permet d'évaluer l'environnement comme sûr.

La sérénité est un sentiment qui peut être associée au calme et à la tranquillité. Nous définissons la sérénité par l'absence d'anxiété et de tension interne et par l'habilité pour un individu d'apprécier les expériences vécus.

La peur est une émotion provoquée par ce qui peut être perçu comme une menace. Elle cause des réponses comportementales comme la fuite, la tétanisation ou la dissimulation pour éviter cette menace.

La colère est une émotion qui apparaît en réponse à une menace ou à des injustices, quand quelque chose ou quelqu'un est responsable de cette situation. Elle motive les gens à se protéger et à combattre.

La tristesse est une réponse émotionnelle associée à la perte irrévocable de quelque chose perçu comme important et aimé. Elle combine les sentiments liés à la perte, à l'impuissance et peut entraîner des pleurs.

Le dégoût correspond au sentiment de répulsion et le besoin d'éviter une situation ou un objet considéré comme déplaisant.

L'anxiété se caractérise par un long sentiment d'inquiétude, des ruminations et des plaintes somatiques comme des tensions musculaires ou de la fatigue en réponse à des événements anticipés.

Si vous considérez que le mot n'évoque pas du tout l'émotion en question, entourez le chiffre 1. Si vous considérez que le mot évoque fortement l'émotion en question, entourez le chiffre 5. Les chiffres intermédiaires vous permettent de nuancer votre réponse.Si vous ne connaissez pas la signification du mot et que vous ne pouvez pas donner d'évaluation, cochez la case : "je ne connais pas ce mot». Il n'y a pas de bonne ou de mauvaise réponse, répondez aussi spontanément que possible.

Merci pour votre collaboration.

\section{Instructions (translation from French)}

We are going to present you with a list of words.

For each of these words, we ask you to indicate to what extent they evoke the following 10 emotions: awe, fear, satisfaction, anger, amusement, disgust, serenity, sadness, excitement, and anxiety.

Each emotion was defined orally by one of the experimenters as follows:

Awe is a feeling associated with amazement, as though, when someone feels that emotion, his mind is stretching and his understanding of the universe is expanding; a feeling that 
freezes a person in one spot and makes him want to examine everything about his experience.

Amusement is an emotion associated with play, humor. It usually appears when someone wants to laugh and joke with others.

Excitement is a positive response given to novelty and new challenges. It appears when a goal is set and perceived as interesting and put a person in dispositions to react to the different stimulus of the environment.

Contentment is the feeling of accomplishment of one's situation. It appears when someone's needs have been fulfilled. It brings the person to feel united with what is around him and to evaluate the environment as safe.

Serenity is a feeling that can be associated with calm and tranquility. We define serenity by the absence of anxiety and of all internal tension and the ability for an individual to enjoy his present experiences.

Fear is an emotion provoked by what a person perceives as a threat. It causes fast behavioral responses, like running away, freezing or hiding in order to avoid this threat.

Anger is an emotion evoked in response to a threat or injustices, when there is someone or something to blame for this situation. It motivates people to protect themselves and fight.

Sadness is an emotional response associated with the irrevocable loss of something perceived as important and loved. It combines the feelings of loss, helplessness and can provoke crying as a reaction.

Disgust corresponds to the feeling of revulsion and the need to avoid a situation or an object considered unpleasant.

Anxiety is characterized by a long-lasting feeling of worry, ruminations and somatic complaints like muscular tensions or tiredness in responses to anticipated events.

If you consider that the word does not evoke the emotion in question at all, circle the number 1 . If you consider that the word strongly evokes the emotion in question, circle the number 5 . The intermediate numbers allow you to qualify your answer. If you do not know the meaning of the word and cannot give evaluation, check the box: "I do not know the word". There is no right or wrong answer, respond as spontaneously as possible.

Thank you for your cooperation.

\section{References}

Alario, F. X., \& Ferrand, L. (1999). A set of 400 pictures standardized for French: Norms for name agreement, image agreement, familiarity, visual complexity, image variability, and age of acquisition. Behavior Research Methods, Instruments, \& Computers, 31(3), 531-552. https://doi.org/10.3758/BF03200732

Bonin, P. (2003). Production verbal de mots : Approche cognitive. Bruxelles : De Boeck.
Bonin, P., Méot, A., \& Bugaiska, A. (2018). Concreteness norms for 1, 659 French words: Relationships with other psycholinguistic variables and word recognition times. Behavior Research Methods, 50, 2366-2387. https://doi.org/10.3758/s13428-018-1014-y

Bonin, P., Méot, A., Ferrand, L., \& Bugaiska, A. (2015). Sensory experience ratings (SERs) for 1,659 French words: Relationships with other psycholinguistic variables and visual word recognition. Behavior Research Methods, 47, 813-825. https://doi.org/10.3758/ s13428-014-0503-x

Bonin, P., Méot, A., Ferrand, L., \& Roux, S. (2011). L'imageabilité : normes et relations avec d'autres variables psycholinguistiques. L'Année psychologique, 111(2), 327-357. https://doi.org/10.4074/ S0003503311002041

Bradley, M. M., Codispoti, M., Sabatinelli, D., \& Lang, P. J. (2001). Emotion and motivation II: Sex differences in picture processing. Emotion, 1(3), 300-319.

Bradley, M.M., \& Lang, P.J. (1999). Affective norms for English words (ANEW): Stimuli, instruction manual and affective ratings (Technical Report No. C-1). Gainesville, FL: University of Florida, NIMH Center for Research in Psychophysiology

Briesemeister, B.B., Kuchincke, L., \& Jacobs, A.M. (2011). Discrete emotion norms for nouns: Berlin affective word list (DENNBAWL). Behavior Research Methods, 43(2), 441-448. https://doi. org/10.3758/s13428-011-0059-y

Busing, F.M.T.A., Commandeur, J.J.F., \& Heiser, W.F. (1997). PROXSCAL: a multidimensional scaling program for individual differences scaling with constraints, in Bandilla, W and Faulbaum, F. Softsta'97: Advances in Statistical Software. Stuttgart, Germany: Lucius.

Darwin, C. R. (1872). The expression of the emotions in man and animals. London: John Murray. $1^{\text {st }}$ edition.

Desrochers, A., \& Thompson, G.L. (2009). Subjective frequency and imageability ratings for 3,600 French nouns. Behavior Research Methods, 41, 546-557. https://doi.org/10.3758/BRM.41.2.546

Diener, E., Scollon, C.N., \& Lucas, R.E. (2003). The evolving concept of subjective well-being: The multifaceted nature of happiness. Advances in Cell Aging and Gerontology, 15, 187-219. https:// doi.org/10.1016/S1566-3124(03)15007-9

Eilola, T. M., \& Havelka, J. (2010). Affective norms for 210 British English and Finnish nouns. Behavior Research Methods, 42(1), 134-140. https://doi.org/10.3758/BRM.42.1.134

Ekman, P. (1993). Facial expression and emotion. American Psychologist, 48(4), 384-392. https://doi.org/10.1037/0003-066X. 48.4.384

Fairfield, B., Ambrosini, E., Mammarella, N., \& Montefinese, M. (2017). Affective norms for Italian words in older adults: Age differences in ratings of valence, arousal and dominance. PLoS ONE, 12(1). https://doi.org/10.1371/journal.pone.0169472

Ferrand, L., Bonin, P., Méot, A., Augustinova, M., New, B., Pallier, C., \& Brysbaert, M. (2008). Age of acquisition and subjective frequency estimates for all generally known monosyllabic French words and their relation to other psycholinguistic variables. Behavior Research Methods, 40, 1049-1054. https://doi.org/10.3758/BRM.40.4.1049

Ferré, P., Guasch, M., Martinez-Garcia, N., Fraga, I., \& Hinojosa, J. A. (2017). Moved by words: Affective ratings for a set of 2,266 Spanish words in five discrete emotion categories. Behavior Research Methods, 49(3), 1082-1094. https://doi.org/10.3758/ s13428-016-0768-3

Ferré, P., Guasch, M., Moldovan, C., \& Sánchez-Casas, R. (2012). Affective norms for 380 Spanish words belonging to three different semantic categories. Behavior Research Methods, 44, 395-403. https://doi.org/10.3758/s13428-011-0165-x

Fredrickson, B. L. (1998). What good are positive emotions? Review of general psychology, 2(3), 300-319. https://doi.org/10.1037/10892680.2.3.300 
Fredrickson, B. L. (2013). Positive emotions broaden and build. Advances in Experimental Social Psychology, 47, 1-53. https://doi. org/10.1016/B978-0-12-407236-7.00001-2

Fredrickson, B. L., \& Branigan, C. (2005). Positive emotions broaden the scope of attention and thought-action repertoires. Cognition and Emotion, 19(3), 313-332. https://doi.org/10.1080/ 02699930441000238

Gobin, P., Camblats, A.-M., Faurous, W., \& Mathey, S. (2017). Une base de l'émotionnalité (valence, arousal, catégories) de 1286 mots français selon l'âge (EMA). Revue Européenne de Psychologie Appliquée, 67(1), 25-42. https://doi.org/10.1016/j.erap.2016.12.001

Griskevicius, V., Shiota, M. N., \& Neufeld, S. L. (2010). Influence of different positive emotions on persuasion processing: A functional evolutionary approach. Emotion, 10(2), 190-206. https://doi.org/10. 1037/a0018421

Guasch, M., Ferré, P., \& Fraga, I. (2015). Spanish norms for effective and lexico-semantic variables for 1400 words. Behavior Research Methods, 48(4), 1358-1369. https://doi.org/10.3758/s13428-0150684-y

Hinojosa, J. A., Martinez-Garcia, N., Villalba-Garcia, C., FernandezFolgueiras, U., Sanchez-Carmona, A., Pozo, M.A., \& Montoro, P.R. (2016). Affective norms of 875 Spanish words for five discrete emotional categories and two emotional dimensions. Behavior Research Methods, 48(1), 272-284. https://doi.org/10.3758/ s13428-015-0572-5

Hinojosa, J. A., Rincón-Pérez, I., Romero-Ferreiro, M. V., MartínezGarcía, N., Villalba-García, C., Montoro, P. R., \& Pozo, M. A. (2016). The Madrid Affective Database for Spanish (MADS): Ratings of Dominance, Familiarity, Subjective Age of Acquisition and Sensory Experience. PloS One, 11(5), e0155866. https://doi. org/10.1371/journal.pone. 0155866

Imbir, K. K. (2015). Affective norms for 1,586 Polish words (ANPW): Duality-of-mind approach. Behavior Research Methods, 47(3), 860-870. https://doi.org/10.3758/s13428-014-0509-4

Kapucu, A., Kılıç, A., Özkılıç-Kartal, Y., \& Sarıbaz, B. (2018). Turkish emotional word norms for arousal, valence and discrete emotion categories, Psychological Reports, 1-22. https://doi.org/10.1177/ 0033294118814722

Keltner, D., \& Haidt, J. (2003). Approaching awe, a moral, spiritual, and aesthetic emotion. Cognition and emotion, 17(2), 297-314. https:// doi.org/10.1080/02699930302297

Kousta, S.-T., Vigliocco, G., Vinson, D. P., Andrews, M., \& Del Campo, E. (2011). The representation of abstract words: Why emotion matters. Journal of Experimental Psychology: General, 140, 14-34. https://doi.org/10.1037/a0021446

Kruskal, J. B., \& Wish, M. (1978). Multidimensional scaling. Sage Publications, Beverly Hills, California.

Lachaud, C. M. (2007). CHACQFAM: Une base de données renseignant l'âge d'acquisition estimé et la familiarité pour 1225 mots monosyllabiques et bisyllabiques du Français. L'Année Psychologique, 1, 39-63.

Lang, P.J., Bradley, M.M., \& Cuthbert, B.N. (2005). International Affective Picture System (IAPS): affective ratings of pictures and instruction manual. Florida: NIMH, Center for the Study of Emotion \& Attention.

Larsen, R. J., Mercer, K. A., Balota, D. A., \& Strube, M. J. (2008). Not all negative words slow down lexical decision and naming speed: Importance of word arousal. Emotion, 8(4), 445-452. https://doi. org/10.1037/1528-3542.8.4.445

Levenson, R.W. (2003). Blood, Sweat, and Fears the Automatic Architecture of Emotion. Annals New-York Academy of Sciences, 1000, 348-366. https://doi.org/10.1196/annals.1280.016

Lewis, M., Haviland-Jones, J. M., \& Barrett, L. F. (2008). Handbook of emotions, 3rd ed (M. Lewis, J. M. Haviland-Jones, \& L. F. Barrett (Eds.). The Guilford Press.
Mikels, J.A., Fredrickson, B.L., Larkin, G.R., Lindberg, C.M., Maglio, S.J., \& Reuter-Lorenz, P.A. (2005). Emotional category data on images from the IAPS. Behavior Research Methods, 37(4), 626630. https://doi.org/10.3758/BF03192732

Monnier, C., \& Syssau, A. (2014). Affective norms for French words (FAN). Behavior Research Methods, 46(4), 1128-1137. https://doi. org/10.3758/s13428-013-0431-1

Montefinese, M., Ambrosini, E., Fairfield, B., \& Mammarella, N. (2014). The adaptation of the Affective Norms for English Words (ANEW) for Italian. Behavior Research Methods, 46(3), 887-903. https://doi. org/10.3758/s13428-013-0405-3

Moors, A., De Houwer, J., Hermans, D., Wanmaker, S., van Schie, K., Van Harmelen, A.-L., De Schryver, M., De Winne, J., \& Brysbaert, M. (2013). Norms of valence, arousal, dominance, and age of acquisition for 4,300 Dutch words. Behavior Research Methods, 45(1), 169-177. https://doi.org/10.3758/s13428-012-0243-8

Osgood, C. E., Suci, G. J., \& Tannenbaum, P. H. (1957). The measurement of meaning. Urbana: University of Illinois Press.

Panksepp, J. (1998). Affective Neuroscience: The Foundations of Human and Animal Emotions, New York: Oxford University Press.

Panksepp, J. (2007). Affective consciousness, in Velmans, M. \& Schneider, S. (eds.) The Blackwell Companion to Consciousness, pp. 114-129, Malden, MA: Blackwell.

Panksepp, J. \& Biven, L. (2012). Archaeology of Mind: Neuroevolutionary Origins of Human Emotions, New York: Norton.

Ponz, A., Montant, M., Liegeois-Chauvel, C., Silva, C., Braun, M., Jacobs, A. M., \& Ziegler, J. C. (2013). Emotion processing in words: a test of the neural re-use hypothesis using surface and intracranial EEG. Social Cognitive and Affective Neuroscience, 9(5), 619-627. https://doi.org/10.1093/scan/nst034

Redondo, J., Fraga, I., Padrón, I., \& Comesaña, M. (2007). The Spanish adaptation of ANEW (Affective Norms for English Words). Behavior Research Methods, 39, 600-605. https://doi.org/10.3758/ BF03193031

Ric, F., Alexopoulos, T., Muller, D., \& Aubé, B. (2013). Emotional norms for 524 French personality-trait words. Behavior Research Methods, 45, 414-421. https://doi.org/10.3758/s13428-012-0276-z

Riegel, M., Wierzba, M., Wypych, M., Zurawksi, L., Jednorog, K., Grabowska, A., \& Marchewka, A. (2015). Nencki Affective Word List (NAWL): The Cultural Adaptation of the Berlin Affective Word List-Reloaded (BAWL-R) for Polish. Behavior Research Methods, 47(4), 1222-1236. https://doi.org/10.3758/s13428-0140552-1

Russell, J. A. (1980). A circumplex model of affect. Journal of personality and social psychology, 39(6), 1161-1178. https://doi.org/10. 1037/h0077714

Russell, J. A. (2003). Core affect and the psychological construction of emotion. Psychological Review, 110(1), 145-172. https://doi.org/ 10.1037/0033-295X.110.1.145

Schmidtke, D. S., Schröder, T., Jacobs, A. M., \& Conrad, M. (2014). ANGST: Affective norms for German sentiment terms, derived from the affective norms for English words. Behavior Research Methods, 46(4), 1108-1118. https://doi.org/10.3758/s13428-0130426-y

Shiota, M., Campos, B., Oveis, C., Hertenstein, M. J., Simon-Thomas, E., $\&$ Keltner, D. (2017). Beyond happiness: Building a science of discrete positive emotions. American Psychologist, 72(7), 617 643. https://doi.org/10.1037/a0040456

Soares, A. P., Comesaña, M., Pinheiro, A. P., Simões, A., \& Frade, C. S. (2012). The adaptation of the Affective Norms for English words (ANEW) for European Portuguese. Behavior Research Methods, 44(1), 256-269. https://doi.org/10.3758/s13428-011-0131-7

Stadthagen-González, H., Ferré, P., Perez-Sanchez, M, A., Imbault, C., \& Hinojosa, J. A. (2018). Norms for 10,491 Spanish words for five discrete emotions: Happiness, disgust, anger, fear, and sadness. 
Behavior Research Methods, 50(5), 1943-1952. https://oi.org/10. 3758/s13428-017-0962-y

Stevenson, R. A., Mikels, J. A., \& James, T. W. (2007). Characterization of the Affective Norms for English Words by discrete emotional categories. Behavior Research Methods, 39, 1020-1024. https:// doi.org/10.3758/BF03192999

Strauss, G. P., \& Allen, D. N. (2008). Emotional intensity and categorisation ratings for emotional and nonemotional words. Cognition and emotion, 22(1), 114-133. https://doi.org/10.1080/ 02699930701319154

Sturrock, K., \& Rocha, J. (2000). A multidimensional scaling stress evaluation table. Field methods, 12(1), 49-60. https://doi.org/10.1177/ $1525822 X 0001200104$

Syssau, A., \& Laxén, J. (2012). The influence of semantic richness on the visual recognition of emotional words. Canadian journal of experimental psychology, 66(1), 70-78. https://doi.org/10.1037/a0027083
Võ, M. L.-H., Conrad, M., Kushinke, L., Urton, K., Hofmann, M.J., \& Jacobs, A. M. (2009). The Berlin Affective Word List Reloaded (BAWL-R). Behavior Research Methods, 41(2), 534-538. https:// doi.org/10.3758/brm.41.2.534

Võ, M. L.-H., Jacobs, A. M., \& Conrad, M. (2006). Cross-validating the berlin affective word list. Behavior Research Methods, 38, 606-609. https://doi.org/10.3758/BF03193892

Wierzba, M., Riegel, M., Pucz, A., Leśniewska, Z., Dragan, W. Ł., Gola, M., Jednoróg, K., \& Marchewka, A. (2015). Erotic subset for the Nencki Affective Picture System (NAPS ERO): cross-sexual comparison study. Frontiers in psychology, 6, 1336. https://doi.org/10. 3389/fpsyg.2015.01336

Wundt, W. (1896). Grundriss der Psychologie. Leipzig: Alfred Kroner.

Publisher's note Springer Nature remains neutral with regard to jurisdictional claims in published maps and institutional affiliations. 